\title{
Pedagogical Reasoning, Creativity and Cooperative Learning in the Visual Art Classroom
}

Kerrie Corcoran and Cheryl Sim Cannon Hill Anglican College and Griffith University, Brisbane Australia

\begin{abstract}
This article reports on an action research study that combined a process-product approach to improving learning with reflective practice. In Queensland, the school subject of senior secondary Visual Art is based on a state curriculum document that sets out standards against which teachers assess each student's creative ability. A pedagogy that supports the development of creativity is integral to student success. This action research centered around the explicit teaching of a cooperative learning model that set out to facilitate senior secondary students' creativity in art making. One of us examined her teaching for creativity while she implemented the model. The action research required Corcoran to examine her teaching for creativity when she decided to implement a particular model of cooperative learning. Through analysis of the evidence collected, Corcoran and Sim identify the process whereby Corcoran acknowledged the role of her assumptions about learners and content, in her pedagogical decision-making. As a result, the finding was that learning and teaching for creativity can be achieved successfully when teachers understand the nature of their own pedagogical reasoning.
\end{abstract}

\section{Keywords:}

Visual Art

pedagogical reasoning

cooperative learning

creativity

knowledge-in-action

\section{Introduction}

The process of teaching entails a variety of decisions. In 1987, Shulman published his influential paper on categorizing the informing knowledge base of the practitioner. 
Among other things he identified the category that is the distinctive province of the teacher (the unique amalgam of content and pedagogical knowledge), and the complexity of the thinking underlying practitioner decision-making. Shulman termed this process pedagogical reasoning. This paper draws on a larger study Corcoran conducted into the development of creative thinking in young adults in art classrooms. It focuses mainly on the process of pedagogical reasoning when action research is conducted into the teacher's knowledge-in-action as she strives to enhance the creative thinking and collaboration of her students.

Literature advocating arts education makes many claims. Among them it is argued that arts education has the capacity to stimulate creativity and build teamwork and communication skills (MCEETYA 2008). However these benefits do not automatically occur just because secondary students participate in Visual Art lessons for five years. As Eisner and Day (2004:6) observed: 'art teaching is relatively understudied by researchers and scholars’.

The paper begins by explaining the background to the study: then it describes the context and content of the action research; finally it relates the key findings to theory about pedagogical reasoning. Young people across the western industrialized world are strongly influenced by powerful visual technologies, often experiencing these in isolation rather than as part of communities. For this reason, it is important for Visual Arts teachers to examine the pedagogical reasoning they engage in to enhance these students’ creative thinking and collaboration in classroom settings.

\section{Teaching for creative thinking}

The concept of 'creativity' is broad in scope and difficult to define. Consequently, there is no single, clear indication of how it can be enhanced in a teaching 
environment. However, models exist that can be applied in Visual Art classrooms. While the importance of internal determinants on creativity has been stressed in the literature, much less emphasis has been placed on external determinants. Investigations have tended to focus on research into creative persons and there has been little appreciation of the contextual situations or circumstances that cultivate creative behaviour (Cropley 2001; Brown 1989).

Recently, social psychologists have endeavoured to understand and explain how particular social and environmental conditions influence individuals' creative behaviour. Research by Amabile (1986) strongly indicates that given the right circumstances, certain strategies can improve creative behaviour and thus performance. It supports the argument that creativity can be taught.

Csikszentmihalyi (1988) argued that a 'congenial' environment within the social system of classrooms is essential for learning creativity. Increasingly research into learning emphasizes the importance of social influences (e.g. Cropley 2006). Learning in classrooms is not done in isolation; thus it is important to understand decisions teachers take to change social activity in classroom settings. Using this socio-cognitive perspective, Corcoran developed pedagogy for enhancing creative thinking in her Visual Art classrooms. The focus of her action research project was on improving her practice in order to develop the senior school art students' creativity. The intention was to first establish in students a belief in their ability for creative thinking. Once achieved, the premise was that in particular those students who were at risk of failing in this subject area would become willing to participate in making art.

In her role as teacher Corcoran provided a 'structure' to support cooperative learning. In the initial stages of the project she chose to adopt a 'process-product' 
approach to her teaching and apply a creative problem-solving model developed by Parnes (1967). Her starting point was to question the extent to which this model provided students with a framework for solving problems at the conceptual stage of making. She hypothesized that a structured approach would help them because it provides a concrete process through which students can gauge their progress when developing their ideas for their art productions.

\section{Parnes’ creative problem solving model}

The approach, formally known as Creative Problem Solving (CPS), originated five decades ago, with the work of Osborn (1953). Since then, the approach has evolved as it has been applied by researchers in different contexts. It is commonly used in the field of gifted education (Treffinger and Isaksen 2005). Distinctively in the study reported in this paper, Corcoran, was most concerned with engaging students who were at risk of becoming disengaged in the senior Visual Art classroom. These students believed they were not academically able. As her starting point, Corcoran established the hypothesis that these students in particular could benefit from her application of a clear theoretical structure.

While acknowledging the evolution of CPS over time (e.g. Isaksen, Dorval and Treffinger 2000), Corcoran elected to try out an earlier five-stage linear approach. Parnes had applied a revised version of Osborn's original framework within a secondary school context. Further, Cropley (2001) had established that this resulted in positive outcomes in secondary school students' creative problem solving when it was embedded within learning. Parnes’ model became the focus of Corcoran's action research into her own practice and was the starting point for considering her own pedagogical position. 
Parnes understood good ideas as occurring increasingly in the later stages of the creative thinking process. He stated that:

a non-creative problem-solver gets an idea, sees it as a possible solution to his (sic) problem, and settles for it without further ado. The creative problem-solver is not satisfied with (the) first idea. (Parnes and Harding 1962: 190)

In his view what could be termed 'delayed' thinking is the key to generating more creative ideas. The suggestion that not jumping in and assuming a first solution was one that Corcoran undertook, this was grounded in research by Osborn (1953), and Gordon (1971).

The following is an outline of the five steps Corcoran implemented in her study:

i) Fact finding: finding out more information about the problem.

ii) Problem finding: the problem has to be clarified, by focusing on sub-problems that add definition to it.

iii) Idea finding: all possible ideas for the problem are listed. A list is created of all 'possible best' solutions through group brainstorming.

iv) Solution finding: criteria are developed to evaluate each of the previously generated ideas regarded as potentially valuable.

v) Acceptance finding: involves selling the idea to others and getting them to identify with the solution as the 'best possible' alternative.

The action research project was designed with the aim of understanding the implications of using this theoretical structure in depth. It is at this point that pedagogy moves from a process-product approach into a reflective practitioner stance, in which a teacher examines not only her practice but also the reasoning behind it. 


\section{The action research project}

Schön (1983) established the importance of acknowledging 'knowledge-in-action' in other words, knowledge that is inherent in professional action. Schön also argued that it is possible to recognize 'reflection-in-action' when adjustments to action are made through direct experience. As Schön (1983) stated:

When someone reflects-in-action, he (sic) becomes a researcher in the practice context. He is not dependent on the categories of established theory and technique, but constructs a new theory of the unique case. His enquiry is not limited to deliberation about means, which depends on a prior agreement about ends. He does not keep means and ends separate, but defines them interactively as he frames a problematic situation. He does not separate thinking from action .... His experimenting is a kind of action; implementation is built into his enquiry. (Schön 1983:68)

The nature of Corcoran's project, in which a particular theory guided exploration of practice in a local context, aligns well with the action research methodology. It took place over a period of three years with two different cohorts of students. Action research enables teachers to become more analytical about their practice, view it in a different light and find ways of improving it. The action research framework was critical for Corcoran, who was fully aware that, as an art educator, she shaped her students' visual products and thus must ask the question: How am I controlling my students’ creativity? (Wilson 2004).

\section{The context}

The participants were fifty students aged between sixteen and eighteen, in two different schools. The action research had two spirals. A spiral is the structural device used in action research to group together investigation and reflection (through a series of cycles of planning, action and reflection) on something the teacher understands 
need to 'change'. In this study, the issues were related to enhancing student creativity. There were two spirals of action research focusing on Corcoran's teaching and learning in Visual Art classrooms. The first spiral comprised of teaching visual art to twenty four students over a twelve month period in 2000. The second operated with another fifteen students in the same site (Site 1) in 2001. The involvement of a further eleven students at a different site (Site 2) finalized this spiral in 2003. Research literature about learning and Parnes’ Creative Problem Solving (CPS) model provided the theoretical framework and data analysis tools.

Evidence of change in student learning and teacher practice was recorded in a teacher field log, through student interviews and in classroom interactions. The field log included photographs, lesson plans, personal reflections, evidence of student problem solving and completed artwork. The interviews with students and colleagues, which sought to establish their views about the strategies implemented within the study, were audio taped. Written comments about their experiences were collected from all the students at the end of each cycle. As they used the strategies designed to enhance their creativity, their classroom interactions were videotaped. Triangulating the students, colleagues and the teacher researcher views, led to the identification of conceptual 'themes'. The understandings gained from analysing this evidence were re-examined during the last cycle at Site 2. Through video-stimulated recall interviews with the students in Site 2, a further technique was used to identify how the initial conceptual 'themes' from Site 1 had formed over time and in a different place (Site 2).

When Corcoran used action research to investigate a strategy for improving creative thinking and cooperation she included the students as co-researchers. It was their responses to her implementation of the teaching strategies that established them 
as co-researchers. Importantly their role in this was understood to contribute to the establishment of a cooperative learning environment.

\section{Student learners as participants in action research}

Action research is particularly suited to situations where educators commit to improving students' active participation in learning. An action research design requires participatory activity. As this study setting was the classroom, students were fully informed about it and acted as critical informants. Consequently, the interventions responded to student input. Students in the first spiral in particular suggested changes to the implementation of the Parnes’ CPS model.

It is possible to argue that utilizing this model makes the process of conceptualizing art works too structured and does not allow sufficient freedom for student exploration. However, there was evidence from this study that the steps are positive, for low achievers at least, in offering a concrete guide for cognitive thinking. All the student participants who found it challenging to come up with creative ideas for artwork appreciated the structured steps in the Parnes model.

The interview data indicated that students preferred to use cooperative learning in Parnes' 'fact finding' stage and at the beginning of 'idea finding' stage. But experience suggested this should occur individually in the later phases of 'idea finding'. Cooperative learning was most appreciated in the later stages of 'solution finding'; when students bounced ideas off peers and looked for feedback to direct them towards their most creative solutions. The stage of 'acceptance finding' saw students engaging with the teacher-researcher, as well as achieving resolution individually. 
One finding was that students began to reflect on and take ownership of their learning processes. As participants in the action research, they assessed the use and potential of cooperative learning as a strategy for enhancing creativity and to this extent, the students had developed the ability to process their own learning metacognitively. The combination of the Problem Solving model with the explicit involvement of students in action research resulted in the development of selfregulated learning.

There was evidence from the interviews, questionnaires and classroom observations that the students involved in the study moved quickly to become what Zimmerman (1989) states as being: self-regulated learners. This significant outcome suggests that the Parnes' model enabled students to assume the autonomy that is necessary to enhance creative ideas.

As they worked with and evaluated the model as co-researchers, they informed the teacher-researcher of the need for change where it was problematic. Their research role seemed to improve their motivation. They were able to express their understanding of how they learned, not just what, and actively participate in their own learning processes and achieve personal goals. Through cooperative learning, they gained confidence planning the problem solving process and keeping on task as they conceptualized ideas while using the model. Andrew, a student involved in the study, when asked in an interview about his reflection on the CPS model, stated simply 'it keeps me focused'.

Using action research to apply and evaluate a problem solving strategy meant students no longer relied on teacher instructions. A strong inter-relationship between process and outcome was evident in the questionnaire responses. The Parnes model provided teacher and students with common ground for discussing creative thinking 
and a degree of confidence building that was mutually beneficial, and assured the teacher her pedagogical decisions were well informed. Observation of the artwork suggested students felt confident of progress. Their questionnaire responses also suggested that the steps in the model provided a useful reference point for struggling students who suffered from 'artist block' or experienced 'mental ruts'.

Andrew’s story supports this claim. In the past he had struggled in Visual Art. However, when he experienced 'artist block' he retraced his steps using the Parnes CPS model and was able to work autonomously to overcome this problem. In other words, he took ownership of his learning. He recognized which part of the problem solving he was having difficulty with, and was able to rectify this by searching out answers independently. Andrew became increasingly confident in his ability to identify and address problems.

As the students began to understand the steps involved and became competent at implementing them, they used the CPS model according to personal need and flexibility became a part of the pedagogy. There was evidence from the study that their participation as co-researchers in the action transformed the pedagogy from what could have been a 'process-product' approach to a reflective practitioner approach. Action research enables teachers to become more analytical about their practice, thus they can view their practice in a different light and develop different ways of improving it. For Corcoran, the action research design was critical, for throughout the project she was fully aware that, as Wilson (2004) suggests, as an art educator she was shaping the visual products of her students, and thus must ask the question: How am I controlling my students’ creativity?

There was also evidence from the study that the flexible use of classroom space in Visual Art environments is conducive to cooperative learning. The teacher- 
researcher allowed students to move around the classroom freely. A finding was that for cooperative learning environments to be productive, students need room to move around in an informal setting. However, success is dependent on the guidance they receive for becoming self-regulated learners.

\section{Cooperative learning: collegiality, diversity and accountability}

In analysing all the evidence, the integral part played by the specific learning situation could not be ignored. In this study students who had previously experienced problems developing ideas in the conceptual stage of art making overcame them by means of specific cooperative learning strategies. The study required one author to adapt the Parnes’ CPS model to the particular conditions and contexts of her classroom.

Research by Webb, Nemer, Chizhik and Sugrue (1998) found that group composition has a major impact on the quality of discussion and student achievement. The cooperative learning environment in this action research was characterized by collegiality, diversity and accountability. The most important first step in the study was to establish a collegial environment that offered a social structure of support but at the same time, motivated students to strive for academic success. The problem of non-contributors in group work is well known. In this study the groups were small, consisting of no more than four learners. Research has shown that large groups do not work well because individuals who can be successful contribute very little; this is referred to as ‘free-riding’ (Larey and Paulus 1999; Slavin 1991).

Thus, in Corcoran's study, group formation was a research focus. At first, and following advice in the literature and from colleagues, she did not seek student input on how to form groups. However early on, it became clear that to persist this way would minimize collegiality, obstruct creativity and provide no opportunities for 
establishing links between the cooperative techniques and creative expression. While she felt uneasy about 'going against' the expressed wisdom of practitioner colleagues that friendship groups in classrooms are doomed, Corcoran followed the action research steps. She examined the data informing her of her students' concerns, made the change and included them as participants.

Corcoran’s initial assumptions about successful group learning were challenged by the finding that cooperative learning is most successful with this age group when groups are friendship-based. Emotions and feelings are expressed visually in art, and can be extremely personal. Indeed in other less supportive settings such self-disclosure might be ridiculed. Rebecca, who spoke honestly about why she felt it was better to work with friends, reflects the sensitive nature of these disclosures in this response:

Art is more personal anyway; in sport you're doing the same thing playing the same game. Art, you are going in different directions. Not like you're all trying to copy and draw the same thing. In sport you are.

As a teacher-researcher Corcoran came to the decision during the first cycle to allow friends to form groups. Sharing ideas and techniques this way was worthwhile because the students appeared less inhibited and creative ideas emerged more openly. These findings about friendship groups endorse what Zurmuehlen (1990) says about the 'inner self' becoming more public in Visual Art classrooms. Alexandra for example said she gained 'more direction' with a friend.

When groups were formed so as to reflect student choice as far as possible, another valuable insight emerged about diverse artistic abilities. Cooperative learning offers a more positive environment for students to motivate each other to learn and challenge each other. The study found that learning in cooperative groups, rather than 
individually, enables low achieving students to develop ideas and solve problems more creatively.

Evidence gathered from groups with diverse confidence levels suggested that the cooperative learning experience strongly influenced members' creative thinking. Students who participated in friendship groups with diverse artistic abilities produced more creative ideas when brainstorming and their thinking developed. Milliken, Bartel and Kurtzberg (2003) reported similar findings from their research.

Despite some disagreements, students worked productively on personally set goals while seated with peers in collaborative learning environments. In his interview, Matthew emphasized the importance of input from peers, commenting that, '...they talked to you on your level so it was good.' The strength of collegial learning environments was realized and understood. Importantly, the study demonstrated that establishing a supportive learning environment reduces classroom competition and strengthens the quality of learning. Students became motivated to engage in more productive and creative learning opportunities and were successful as a result of collegiality, not competition.

This result was most obvious in analyses of video taped classroom interactions. Here the researchers could see that some students engaged with others more readily and openly than in the past. Andrew, the low achieving student, recognized the importance and value of collegial work and realized he 'generated more ideas' from being part of a group. The cooperative learning environment created a sense of comradeship. At this point, it is useful to briefly examine the implementation of the problem-solving model the teacher researcher used. 


\section{Conclusions}

As an experienced teacher, Corcoran was aware from past experience that many students in her senior art classrooms struggled to think creatively and develop their artwork. When they tried to solve problems during the conceptual stage of art production, they tended to choose the most obvious or basic solution that came to mind. This led them to underestimate their abilities and undermined their selfconfidence and esteem. The challenge for the teacher was to identify and change the learning style so as to help them think more creatively. Too often their lack of confidence to 'take a chance'; 'go out on a limb' or be radically different obstructed their approach to problem solving. Yet at other times they spent hours in the problemsolving stage but appeared confused and unable to decide what direction to take.

The combination of the Parnes' model with action research produced a positive, dynamic pedagogical environment in this study. The teacher acting as researcher gained insight into the learners' reactions to her reasons for implementing the model and influenced her decision making along the way. Further, she incorporated their input into her teaching and discovered they were willing to invest time into developing their abilities and had the capacity to be interactive and flexible in their learning.

Cooperative learning was successful not only because a well-researched model was introduced into the classroom, but also because the teacher was willing to reflectin-action on its implementation. The study provided evidence that introducing a model successfully requires not only time and effort, but also openness to student input.

Traditionally, teachers direct students through the learning process, and dictate time frames and outcomes. The process of pedagogical decision-making may become 
confined by concern with teacher control and, as a result, teachers become unresponsive to student needs. However in this study students were engaged cooperatively in the creative process, and the teacher made the basis for her decisions explicit to them. As a result, the study demonstrated that thoughtful and collaborative practice influences pedagogical reasoning and subsequently successfully changes teacher and student behaviour. The study established that using a well-structured reflexive approach, which enables student groups to have input, means that teachers and students work together, creativity and their engagement improves.

At times the teacher-researcher admitted to feeling anxious that the requirements of the Visual Art senior syllabus might not be met and students would not complete all the essential tasks. Good time management was essential in order for assessment requirements to be met. However, it was clear that this student cohort produced work that was qualitatively stronger than before using this approach.

Cooperative learning requires adjustments to teaching styles and assumptions about students. Teachers have to come to terms with the idea that students can be engaged productively without constant direction. Their responsibility is to provide clear structures for them to work in teams. Moreover, cooperative learning positions them as active participants in the learning process. In collaboration with the teacher, they determine the path along which their learning will proceed. The outcome of this self-study of a teacher committed to researching her practice was a pedagogy that made explicit to students the theory-practice relationship in art education.

A strong model for reflective practice has been presented. Through analysis of evidence collected during action research, Corcoran was able to investigate complexities within her classrooms while seeking to improve students' creative thinking. Teachers base their pedagogy on a set of assumptions, which combined with 
knowledge of content, learners and pedagogy, lead to decision making on a daily basis. Over time these decisions often culminate in their adopting a particular pedagogical reasoning for their practice. In this study, in an effort to improve her students’ creativity, Corcoran decided to implement a particular model of cooperative learning. In making that decision she identified the need to document and evaluate it. The action research study she put in place did much more than simply examine the process and consequences of the model. It engaged her in an investigation into the influences on her pedagogical decision making.

\section{References}

Amabile, T.M. (1996), Creativity in context, Boulder, CO: Westview Press.

Brown, R.T. (1989). Creativity...what are we to measure? In J.A. Glover, R.R Ronning, and C.R. Reynolds (Eds.) Handbook of creativity. New York: Plenum Press, pp. 3-30.

Cohen, E. (1986), Designing groupwork: Strategies for the Heterogeneous classroom, New York: Teachers College Press.

Cropley, A.J. (2001), Creativity in education and learning, London: Kogan Page.

Cropley, A. (2006), Creativity: A Social Approach, Roeper Review, 28:3, pp. 125130.

Csikszentmihalyi, M. (1988), 'The flow experience and its significance for human psychology', in M. Csikszentmihalyi and I.S. Csikszentmihalyi (eds.), Optimal experience, Cambridge: Cambridge University Press, pp. 15-35.

Eisner, E. and Day, M. (eds.) (2004), Handbook of Research and Policy in Art Education, National Art Education Association (NAEA), pp. 299-328.

Gordon, W.J. (1971), The metaphorical way, Cambridge, Massachusetts: Porpoise Books.

Isaksen, S.G., Dorval, K.B. and Treffinger, D.J. (2000), Creative Approaches to problem solving, second edition, Dubuque, IA: Kendall/Hunt.

Johnson, D.W., and Johnson, R.T. (1987), Learning together and alone, Englewood Cliffs, N.J.: Prentice-Hall. 
Larey, T.S. and Paulus, P.B. (1999), 'Group preference and convergent tendencies in small groups. A content analysis of group brainstorming performances', Creativity Research Journal, 12 : 3 , pp. 175-184.

Milliken, F.J., Bartel, C.A., and Kurtzberg, T.R. (2003), 'Diversity and creativity in work groups', in P.B. Paulus and B.A. Nijstad (eds.) Group creativity, London: Oxford University Press.

Ministerial Council in Education, Employment, Training and Youth Affairs (MCEETYA) (2008), 'National Education and the Arts Statement', http://www.mceetya.edu.au/mceetya/national_education_and_the_arts_statement,209 81.html. Accessed 28 March 2008.

Osborn, A.F. (1953), Applied imagination, New York: Scribner.

Parnes, S.J. (1967), Creative behaviour guidebook, New York: Scribner.

Parnes, S.J., and Harding, H.F. (eds.)(1962), A source book for creative thinking, New York: Charles Scribner's Sons.

Schön, D.A. (1983), The reflective practitioner, New York: Basic Books.

Shulman, L. (1987), 'Knowledge and teaching: Foundations of the new reform', Harvard Educational Review, 57 :Spring Issue , pp.1-22

Slavin, R.E. (1991), 'Synthesis of research on cooperative learning', Educational Leadership, 48:6, pp. 82-85.

Treffinger, D.J. and Isaksen, S.G. (2005), 'Creative Problem Solving: The History, Development, and Implications for Gifted Education and Talent Development', The Gifted Child Quarterly, 49:4, pp 342-353.

Webb, N., Nemer, K., Chizhik, A., and Sugrue, B. (1998), 'Equity issues in collaborative group assessment: Group composition and performance', American Educational Research Journal, 35:4, pp. 607-651.

Wilson, B. (2004), 'Child Art after Modernism: Visual Culture and New Narratives', in E. Eisner, E and M. Day (eds.), Handbook of Research and Policy in Art Education, A Project of National Art Education Association (NAEA), Mahweh, NJ: Lawrence Elbaum Assoc., pp. 299-328.

Zimmerman, B.J. (1989), ‘A social cognitive view of self-regulated learning', Journal of Educational Psychology, 81 (3), pp. 329-339.

Zurmuehlen, M. (1990), Studio art: Praxis, symbol, presence, Reston, VA: National Art Education Association. 


\section{Contributer details:}

Kerrie Corcoran is Head of Faculty The Arts at Cannon Hill Anglican College in Brisbane, Queensland, Australia. She has twenty six years experience teaching Visual Art in both single sex and co-educational schools in the private and government sector. Kerrie was awarded her Ph.D. at Griffith University in 2006. She has a strong commitment to curriculum development and effective pedagogy in the Visual Arts, and her research interests are in developing the creative abilities of Visual Arts secondary students.

Email: kcorcoran@chac.qld.edu.au

Cheryl Sim is Senior Lecturer in the Faculty of Education, Griffith University in Brisbane, Queensland, Australia. She has 25 years of experience in secondary and tertiary teacher education. She completed undergraduate and postgraduate studies in History. Her Ph.D. (1999) investigated the development of pedagogical content knowledge of pre-service history teachers. In the last decade, her research has focused on the knowledge base of teachers, in particular the role of communities of practice and pre-service teacher preparation, and the changing nature of the teaching workforce.

Email: C.Sim@griffith.edu.au 